DE

M E D I C I N A

T R O P I C A L

$\mathrm{DE}$

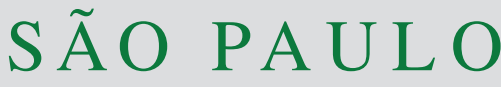

JOURNAL OF THE SÃO PAULO INSTITUTE OF TROPICAL MEDICINE ${ }^{1}$ Universidade Federal de Goiás, Instituto de Patologia Tropical e Saúde Pública, Laboratório de Virologia e Cultivo Celular, Goiânia, Goiás, Brazil

2Universidade Federal do Pará, Instituto de Ciências Biológicas, Belém, Pará, Brazil

${ }^{3}$ Universidade Federal do Tocantins,

Palmas, Tocantins, Brazil

${ }^{4}$ Laboratório Central de Saúde Pública do Estado de Tocantins, Palmas, Tocantins, Brazil

5Universidade de São Paulo, Instituto de Medicina Tropical de São Paulo, São Paulo, São Paulo, Brazil

${ }^{6}$ Ministério da Saúde, Secretaria de Vigilância em Saúde, Departamento de Articulação Estratégica de Vigilância em Saúde, Coordenação Geral de Laboratórios de Saúde Pública, Brasília, Distrito Federal, Brazil

${ }^{7}$ Weill Cornell Medicine, Department of Obstetrics and Gynecology, New York, New York, USA

${ }^{8}$ Vitalant Research Institute, San Francisco, California, USA

'University of California San Francisco, Department of Laboratory Medicine, San

Francisco, California, USA

${ }^{10}$ Instituto Adolfo Lutz, Centro de Virologia, Núcleo de Doenças Entéricas, São Paulo, São Paulo, Brazil

*These authors jointly supervised this work

Correspondence to: Marcelle Silva-Sales Universidade Federal de Goiás, Instituto de Patologia Tropical e Saúde Pública,

Rua 235, Esquina com $1^{\text {a }}$ Avenida, sala 420, CEP 74605-080I, Goiânia, GO, Brazil Tel: +556232096122

E-mail: marcelle.figueira@ufg.br

Adriana Luchs

Instituto Adolfo Lutz, Centro de Virologia,

Núcleo de Doenças Entéricas,

Av. Dr Arnaldo, 355, CEP 01246-902,

São Paulo, SP, Brazil

Tel: +55 1130682909

E-mail: driluchs@gmail.com

Received: 20 October 2020

Accepted: 27 November 2020

\section{Genomic constellation of human Rotavirus A strains identified in Northern Brazil: a 6-year follow-up (2010-2016)}

\author{
Marcelle Silva-Sales ${ }^{1}$, Elcio Leal ${ }^{2}$, Flavio Augusto de Pádua Milagres ${ }^{3,4}$, \\ Rafael Brustulin ${ }^{3,4}$, Vanessa dos Santos Morais ${ }^{5}$, Roberta Marcatti ${ }^{5}$, Emerson \\ Luiz Lima Araújo ${ }^{6}$, Steven S. Witkin ${ }^{5,7}$, Xutao Deng ${ }^{8,9}$, Ester Cerdeira Sabino ${ }^{5}$, \\ Eric Delwart ${ }^{8,9, *}$, Adriana Luchs ${ }^{(10, *}$ Antonio Charlys da Costa ${ }^{5, *}$
}

\section{ABSTRACT}

Surveillance of Rotavirus A (RVA) throughout the national territory is important to establish a more complete epidemiological-molecular scenario of this virus circulation in Brazil. The aim of the present study was to investigate the genetic diversity of RVA strains circulating in Tocantins State (Northern Brazil) during six years of post-vaccination followup (2010-2016). A total of 248 stool samples were screened by next generation sequencing and 107 (43.1\%) nearly full length RVA genome sequences were obtained; one sample was co-infected with two RVA strains (G2/G8P[4]). Six G and P genotypes combinations were detected: G12P[8] strains (78.6\%), as well as the G3P[8] (9.3\%) and G1P[8] (0.9\%) were associated with a Wa-like genogroup backbone. All G2P[4] (5.6\%) and G8P[4] (2.8\%) strains, including the mixed G2/G8P[4] infection (0.9\%) showed the DS-1-like genetic background. The two G12P[4] strains (1.9\%) were associated with distinct genetic backbones: Wa-like and DS-1-like. The phylogenetic analysis revealed the circulation of lineages G1-I, G2-IV, G3-III, G8-I and G12-III, and P[4]-V and P[8]-III of the VP7 and VP4 genes, respectively. Conserved clustering pattern and low genetic diversity were observed regarding VP1-VP3 and VP6, as well as NSP1-5 segments. We identified the same RVA circulation pattern reported in other Brazilian regions in the period of 2010-2016, suggesting that rural and low-income areas may not have a different RVA genotypic distribution compared to other parts of the country. The unique presentation of whole-genome data of RVA strains detected in the Tocantins State provides a baseline for monitoring variations in the genetic composition of RVA in this area.

KEYWORDS: Acute gastroenteritis. Rotavirus A. Brazil. Post-vaccine. Genomic Constellation.

\section{INTRODUCTION}

Rotavirus A (RVA) is the leading cause associated with viral acute gastroenteritis in young children worldwide, accounting for nearly 125,000 deaths annually ${ }^{1}$. The substantial morbimortality associated with RVA infections has led to the development of two oral live vaccines: Rotarix ${ }^{\mathrm{TM}}$ (GlaxoSmithKline Biologicals, Belgium) and RotaTeq $^{\mathrm{TM}}$ (Merck Inc., USA) ${ }^{2}$. So far, nearly 100 countries have introduced at least one RVA vaccine in their National Immunization Programs (NIPs). In Brazil, Rotarix ${ }^{\mathrm{TM}}$ has been included in the NIP in March 2006. Afterwards, a noteworthy impact on the decline of the hospitalizations and deaths associated with infantile gastroenteritis has been widely reported ${ }^{3,4}$.

RVA species together with Rotavirus species B to J are members of the Rotavirus 
genus, Sedoreovirinae subfamily, Reoviridae family and Riboviria realm. The viral genome consists of 11 segments of double-stranded RNA (dsRNA) that encode six structural proteins (VP1-VP4, VP6 and VP7) and six nonstructural proteins (NSP1-NSP5/6), surrounded by a three-layer capsid. RVAs areclassified by a binary system based on their leading neutralization antigens: VP4 (spike protein) and VP7 (capsid glycoprotein). Moreover, a complete genome classification is also used to assign genotypes to each segment, where Gx-P[x]-Ix-Rx-Cx-Mx-Ax-Nx-Tx-Ex-Hx represents the genotypes of VP7-VP4-VP6-VP1-VP2VP3-NSP1-NSP2-NSP3-NSP4-NSP5/6, respectively ${ }^{5}$. G1P[8], G2P[4], G3P[8], G4P[8], G9P[8] and G12P[8] genotypes are the most common human RVA combinations in surveillance investigations conducted worldwide ${ }^{6-8}$.

The next-generation sequencing (NGS) approach is refurbishing viral investigations and NGS applied to whole genome sequencing has the potential to transform RVA molecular epidemiology studies in the near future. In addition, complete or partial sequencing of the $11 \mathrm{RVA}$ genes may elucidate the genetic relationship between RVA strains and their evolutionary process ${ }^{9}$.

Full genomic constellation studies are usually performed with unusual or reassortant RVA strains ${ }^{10}$. However, limited data are available on the complete genome characterization of medically important local strains ${ }^{11}$ especially in Brazil $^{12,13}$. Brazil is a country with distinct demographic characteristics, ranging from densely occupied urban centers to largely rural areas. Consequently, a high degree of diversity among RVA strains is expected between Brazilian regions, so that the establishment of a wide-ranging RVA molecular surveillance in the country is crucial.

The aim of the present study was to investigate the genetic diversity of full genome constellations and to perform phylogenetic analysis of the 11 genes of RVA strains circulating in Tocantins State, Northern Brazil, during six years of post-vaccination surveillance (2010-2016).

\section{ETHICAL APPROVAL}

The Ethical approval was granted by the Faculdade de Medicina of the Universidade de Sao Paulo (CAAE N ${ }^{\circ}$ 53153916.7.0000.0065) and the Centro Universitario Luterano de Palmas - ULBRA (CAAE $\mathrm{N}^{\circ}$ 53153916.7.3007.5516).

\section{MATERIALS AND METHODS}

\section{Study specimens}

The current cross-sectional surveillance study is part of a huge project aiming at screening different gastroenteric viruses in fecal samples collected between 2010 and 2016 in Tocantins State (Northern Brazil) using the metagenomics approach. A total of 233 stool samples were obtained from children $<5$ years old, 3 from children aged 8-15 years old, and 7 from adults aged 20-78 years old, all with gastroenteritis symptoms. In five stool samples, the age of the patients was not informed. This study was carried out without any inclusion or exclusion criteria, therefore, epidemiological data (age, gender, date of symptoms onset, vaccination status) are missing in some patients. The samples were initially sent to the Public Health Laboratory of Tocantins (LACEN-TO) and screened for bacteria (e.g. Escherichia coli and Salmonella sp.), protozoan (e.g., Giardia sp.) and helminths (e.g., Taenia Solum) using conventional parasitological and culture techniques. Frozen and stored $\left(-20{ }^{\circ} \mathrm{C}\right)$ fecal specimens were then shipped to the Institute of Tropical Medicine, University of Sao Paulo (IMT/USP) for the identification of gastroenteric viruses.

\section{Viral metagenomics}

Approximately $50 \mathrm{mg}$ of fecal mass from each sample was diluted in $500 \mu \mathrm{L}$ of Hanks' buffered salt solution and lysing matrix C (MP Biomedicals, USA), homogenized and centrifuged at $12,000 \mathrm{~g}$ for $10 \mathrm{~min}$. Viral RNA was extracted using a ZR and ZR-96 Viral DNA/RNA Kit (Zymo Research, CA, USA), according to the manufacturer's protocol. Nucleic acids were processed using the Illumina MiSeq (San Diego, CA, USA) NGS platform, according to Moore et al. ${ }^{14}$. Shortly, genomic host nucleic acids were removed using a mixture of nuclease enzymes: TURBO DNase and RNase Cocktail Enzyme Mix (Thermo Fischer Scientific, Waltham, MA, USA), Baseline-ZERO DNase (Epicentre, WI, USA), Benzonase (Millipore, Merck, Darmstadt, Germany) and RQ1 RNase-Free DNase and RNase A Solution (Promega, WI, USA). For cDNA synthesis of each sample, AMV Reverse transcriptase (Promega, WI, USA) and random hexamers primers were used according to the manufacturer's instructions and cDNA quantification was performed using QubitR Fluorometer and Qubit ${ }^{\mathrm{TM}}$ dsDNA BR Assay Kit (Invitrogen, California, USA). DNA libraries were prepared using the Nextera XT Sample Preparation Kit (Illumina San Diego, CA, USA) identified by dual barcodes, and sequenced using the Illumina Hi-Seq 2500 Sequencer (Illumina, CA, USA) to generate 126-bp paired-end reads.

\section{Bioinformatics}

The reads were trimmed for primers using Geneious 
software v9.1.8 (Biomatters Ltd., Auckland, New Zealand) and de novo assembled according to Deng et al. ${ }^{15}$. They were also trimmed for removing low-complexity and lowquality regions, other microorganisms and host sequences preceding the de novo assembly. The remaining reads were submitted to BLASTx search against the National Center for Biotechnology Information of non-redundant database (nr). After RVA identification, the generated consensus sequences were confirmed by their alignment to the nucleotide database using the NCBI BLASTn tool with the assembled contigs as query sequences and the 11 RVA gene segments as the target sequences.

\section{Phylogenetic analysis}

RVA sequences were genotyped using Rotavirus A Genotype Determination - ViPR ${ }^{16}$. The identified near-fulllength RVA sequences were aligned with those from the GenBank database using the CLUSTAL W ${ }^{17}$. Phylogenetic trees were reconstructed using the maximum likelihood and model selection implemented in the MEGA software version $7.0^{18}$. Models used in this study were Tamura 3-parameter (T92) + G (VP6, NSP2, NSP3, NSP4 and NSP5), T92 + G + I (VP1, VP2, VP3, VP7 and NSP1), Tamura-Nei (TN93) + G (VP3 and VP6) and of General Time Reversible (GTR) + $\mathrm{G}$ (VP4). The statistical significance at the branch point was calculated by using 2,000 pseudo-replicate datasets.

\section{Accession Numbers}

Nucleotide sequences have been deposited in GenBank under the accession numbers: VP1 (MT579311MT579418), VP2 (MT601127-MT601137), VP3 (MT601138-MT601245), VP4 (MT633351-MT633458), VP6 (MT633243-MT633350), VP7 (MT633136MT633242), NSP1 (MT633459-MT633566), NSP2 (MT601031-MT601126), NSP3 (MT674403-MT674510), NSP4 (MT674295- MT674402) and NSP5 (MT600923MT601030).

\section{RESULTS}

\section{RVA detection}

RVA was detected in $43.1 \%$ (107/248) of the specimens; $59.7 \%$ originated from males and $39.9 \%$ from females. There was no information concerning the gender of four children. The mean and median ages of RVA positive patients were 24.6 months (19 days to 36 years-old) and 18.5 months, respectively. Among the 107 RVA-positive strains, $103(96.3 \%)$ were recovered from children aged 0-60 months, with 35 (32.7\%) collected from children $>2$ years old. Twenty-seven strains (25.2\%) were obtained from children between 1 and 2 years old, 23 (21.5\%) from children aged 6 months to 1-year-old, and 16 (15.0\%) from children under 6 months-old. Among the RVA-positive strains, $60(56.1 \%)$ were recovered from children vaccinated with at least one dose of Rotarix ${ }^{\oplus}$. Eleven (10.3\%) strains were collected from unvaccinated children. Vaccination status was missing in 37 (34.6\%) individuals from the group of samples that tested positive for RVA.

The frequency of RVA detections may vary according to seasonal fluctuations. The Northern region of Brazil is characterized by high temperatures throughout the year, with two well-marked seasons: a rainy (from October to April) and a dry season (from May to September). In our study, $47.7 \%$ (51) of positive samples were collected in the rainy season (from October to April) and 50.5\% (54) in the dry season (from May to September); data regarding the collection time of two fecal samples were missing.

\section{RVA type distribution and genomic constellation}

Nearly full-length genome sequences (coverage $>90 \%$ ) were obtained from the 107 RVA-positive samples, including sample TO-173, co-infected with two RVA strains. Based on VP7 and VP4 genes sequences (classical binary nomenclature), six different genotypes were detected: G12P[8] (78.6\%; 84/107), G3P[8] (9.3\%; 10/107), G2P[4] (5.6\%; 6/107), G8P[4] (2.8\%; 3/107), G12P[4] $(1.9 \% ; 2 / 107)$ and G1P[8] $(0.9 \% ; 1 / 107)$. A mixed infection (G2+G8P[4]) was obtained from one sample $(0.9 \% ; 1 / 107)$ collected in 2010. Throughout the investigation period (2010-2016), the most common genotypic combination was the emergent RVA strain G12P[8], with the G8P[4] strain detected only in 2010.

Genotype constellations regarding all 107 RVA strains presented with a conserved profile. The analysis showed that all G12P[8] strains, as well as the $10 \mathrm{G} 3 \mathrm{P}[8]$ strains and the only G1P[8] strain were associated with the classic Wa-like genogroup backbone (I1-R1-C1-M1-A1-T1-N1E1-H1). All G2P[4] and G8P[4] strains had the DS-1-like genetic background (I2-R2-C2-M2-A2-N2-T2-E6-H2). Surprisingly, the two G12P[4] strains, samples TO-048 and TO-075, were associated with two distinct genetic backbones: Wa-like and DS-1-like, respectively (Table S1, Supplementary Material (SM) section).

\section{Phylogenetic analysis of VP7 and VP4 genes}

The only Brazilian G1 strain identified shared the highest nucleotide and aminoacid similarities with a human 
Bangladeshi strain isolated from a 29 years-old patient hospitalized with acute gastroenteritis in 2002 (RVA/ Human-wt/BGD/Agroj23/2002/G1P[8]). The phylogenetic analysis revealed that this Brazilian G1 strain belonged to lineage I together with other contemporary strains from Asia and Europe and was distinct from Rotarix ${ }^{\mathrm{TM}}$ and Rotateq ${ }^{\mathrm{TM}}$ vaccine strains (Lineage II and III, respectively). In addition, the phylogenetic analysis demonstrated that the seven Brazilian G2 strains clustered together with other strains from different Brazilian Regions (Belem do Para, Acre, Maranhao, Bahia, Rio de Janeiro, Minas Gerais, Espirito Santo and Rio Grande do Sul) isolated between 2006 and 2012 and belonging to lineage IV. The ten Brazilian G3 RVA strains shared a strong nucleotide and aminoacid identity varying from $98.9-100 \%$ and $100 \%$, respectively, among themselves. They grouped into lineage III with strains recovered from human stool samples in the last decade and they are distantly related to recently described equine-like G3P[8] DS-1-like strains (Lineage I). The four G8 RVA strains detected in the present study shared $>99.3 \%$ nucleotide similarity among themselves. Compared to other G8 strains, the Brazilian ones showed a greatest similarity with a G8P[4] strain from Germany (GER1H/2009) and a Croatian G8P[8] strain (CR2006/2006) of 97.8-98.2\% and 97.2-97.5\%, respectively. Lower nucleotide similarity percentages were observed with a variety of other strains of human and animal origin detected worldwide (range: 70.1-86.0\%). The phylogenetic analysis revealed that our Brazilian G8 strains formed three minor clusters, classified within lineage I. The VP7 gene of the 84 Brazilian G12 strains showed 89.4-100\% nucleotide similarity among themselves, all belonging to lineage III. The G12 strains clustered with other G12P[8] strains isolated in Brazil and other countries between 2009 and 2015 (Figure 1, Table S2, SM section).

Analysis of the $12 \mathrm{P}[4]$ strains revealed nucleotide similarities of $95-100 \%$ among themselves, and similarities ranging from $92-99.4 \%$ to other $\mathrm{P}[4]$ strains detected worldwide. All Brazilian P [4] strains belonged to lineage V. The most common VP4 genotype among the Brazilian strains was P[8]. Sequence analysis of 95 P [8] strains showed that the Brazilian P[8] ones had a 96.2-100\% similarity among themselves. These strains have also shown high (86.5-99.3\%) similarity to other P[8] strains isolated globally. Brazilian P[8] strains clustered within lineage III (G1, G3 and G12 strains) (Figure 2, Figure S1, SM section).

\section{Phylogenetic analysis of VP1, VP2, VP3 and VP6 genes}

The VP1 genes were classified within genotypes R1 (in Wa-like strains) or R2 (DS-1-like strains). The phylogenetic analysis showed that the R1 strains formed two distinct clusters. The first one clustered with more recent variants of genotype R1 strains isolated between 2011 and 2017, showing a closer relationship with North American (SSCRTV_00082, 000808444 and VU11-12-192), European (ME650/14, SS64751571), and African (MRC-DPRU1858 and BID1LN) strains. In the second cluster, Brazilian R1 strains grouped with strains isolated in China (R709, L1066 and Y111), Canada (RT020-09), Italy (PR599) and South Africa (MRCDPRU1281) between 2004 and 2013. The R2 phylogenetic analysis has also shown that Brazilian strains clustered within two groups, all closely related to DS-1-like R2 strains isolated worldwide since 2010 (Table S2 and Figure S1, SM section).

Molecular analysis of the Brazilian VP2 genes classified these strains as $\mathrm{C} 1$ (Wa-like) and C2 (DS-1-like) genotypes. Brazilian $\mathrm{C} 1$ and $\mathrm{C} 2$ strains showed nucleotide similarities ranging from $96.6-99.7 \%$ to Wa-like strains and $99.0-100 \%$ to DS-1-like strains, respectively (Table S2 and Figure S1, SM section). The M1 VP3 gene of the Brazilian strains had nucleotide similarities of $96.9-100 \%$ among them. When compared to other Wa-like globally strains, similarities ranged from 97.2-99.9\%. The Brazilian DS-1-like M2 genotype exhibited nucleotide similarities ranging from 96.4-99.2\%, and from 96.6-99.9\% when compared to reference M2 strains. Wa-like and DS-1-like Brazilian strains clustered with recent variants of genotype M1 and M2 strains detected after 2000 (Table S2 and Figure S1, SM section).

The phylogenetic analysis classified the Brazilian strains as VP6 genotypes I1 (Wa-like) and I2 (DS-1-like). A comparison of I1 nucleotide sequences of the Brazilian strains showed similarities ranging from $95.6-100 \%$. Considering other R1 reference strains, similarities ranged from 95.899.8\%. Brazilian I2 strains formed two clusters: (i) RVA/ Human-wt/BRA/TO-251/2010/G8P4 and RVA/Human-wt/ BRA/TO-075/2010/G12P4 strains, clustered together with South African (MRC-DPRU81), Paraguaian (1613SR), Japanese (JP11105) and Brazilian (MA14286) strains (94.398.2\%), and (ii) the other nine VP6 I2 strains were genetically related to previously reported Brazilian strains (RJ12225 and SC19868), and displayed similarities of $92.3-96.7 \%$. Brazilian I2 RVA strains showed similarities of 94.4-99.4\% among them (Table S2 and Figure S1, SM section).

\section{Phylogenetic analysis of non-structural NSP1-NSP5 genes}

Data concerning NSP1-NSP5 genes revealed a conserved clustering pattern among the Brazilian strains. 


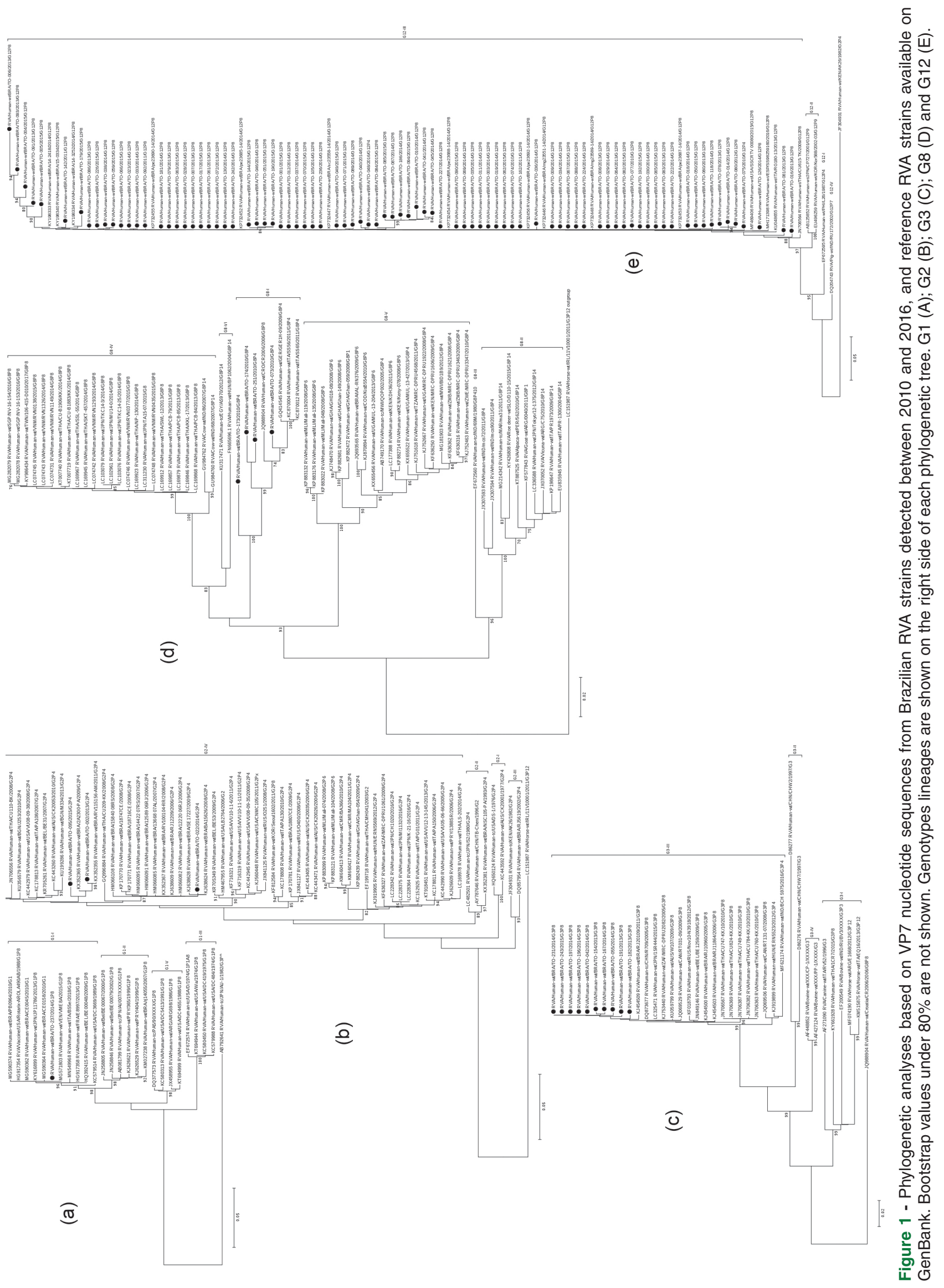




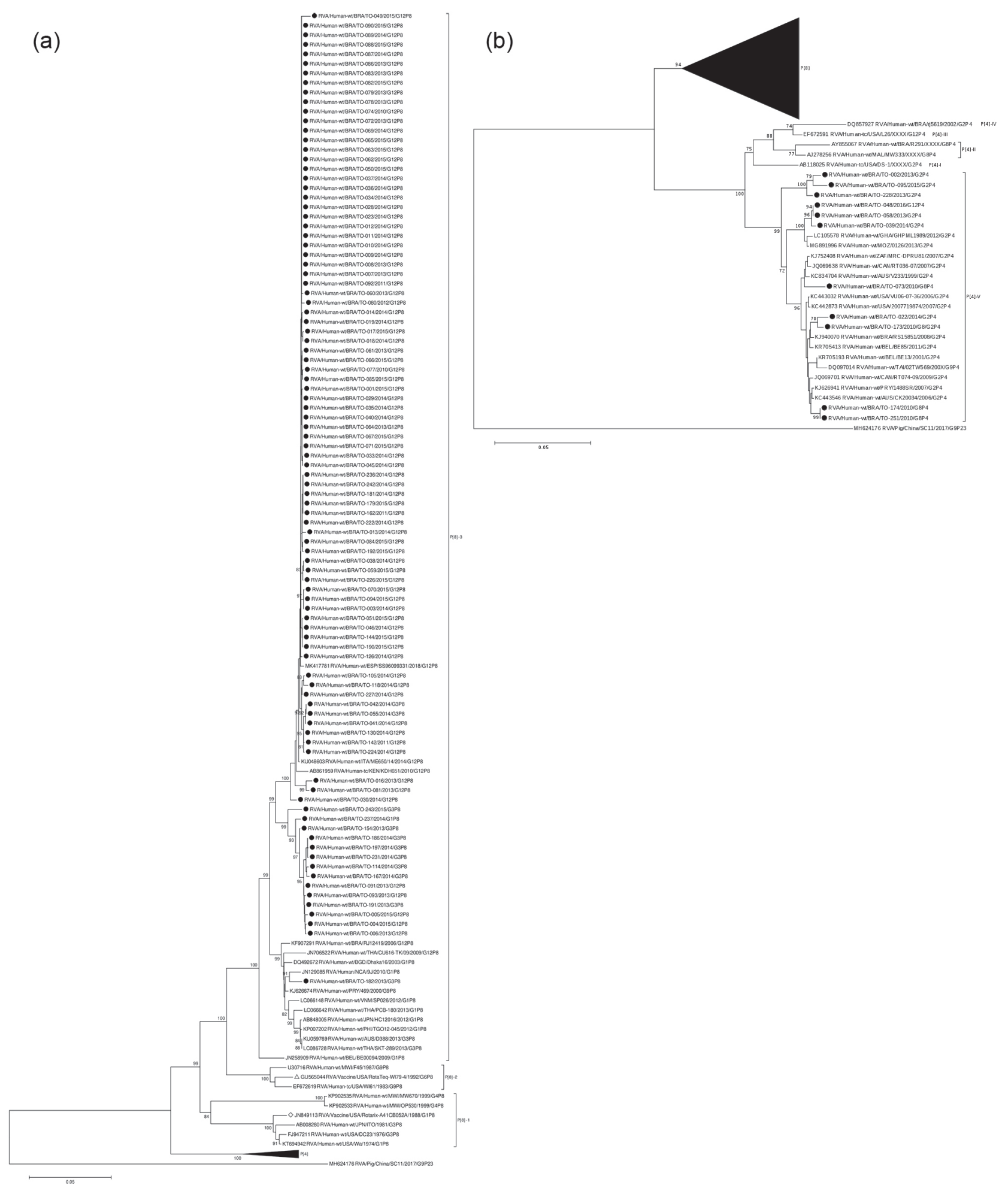

Figure 2 - Phylogenetic analyses based on full-lengthVP4 nucleotide sequences from Brazilian RVA strains detected between 2010 and 2016, and reference RVA strains available on GenBank. Bootstrap values under $80 \%$ are not shown. Genotypes lineages are shown on the right side of each phylogenetic tree. $P[4](A)$ and $P[8](B)$.

Regarding the genotypes, strains were classified as A1, N1, T1, E1 and H1 in GXP[8] strains, for the NSP1, NSP2, NSP3, NSP4 and NSP5 genes, respectively, except for strain
TO-048, which displayed the G12P[4] genotype. GXP[4] strains were classified as A2, N2, T2, E2 and H2, showing a DS-1-like backbone (Table S1 and Figure S1, SM section). 


\section{DISCUSSION}

In the present study, nearly full length genome sequences of 107 Brazilian RVA strains circulating in rural and low-urban areas in Northern Brazil during six years of post-vaccination surveillance (2010-2016) were analyzed. Changing patterns of RVA genotypes over time and the rise of unusual strains are the major concerns for a potential decrease in the efficacy of current RVA vaccines. Studying the whole-genome sequences of RVA strains could provide baseline information to address those concerns in the postRVA vaccine era $^{19}$.

After the Rotarix ${ }^{\mathrm{TM}}$ introduction in 2006 in the National Immunization Program, an increase in G2P[4] detection rate was observed in $\mathrm{Brazil}^{20}$, including in the Northern region ${ }^{21}$. Time series analysis of RVA genotype distribution in Brazil showed a massive predominance of G2P [4] from 2006 to 2010, and a continuous decrease in the detection of this strain since $2010^{4,22}$, consistent with our present data. The DS-1-like backbone of the Brazilian G2P[4] RVA from Tocantins State strains clustered together with recent new global G2P[4] strains, corroborating previous whole-genome analysis conducted in Brazil ${ }^{12,23}$. In the early 2000s, new global G2P [4] RVA strains emerged and became widespread across the globe, replacing the old G2P[4] strains $^{24}$. Based on the VP7 and VP4 genes, the analyzed G2P[4] samples clustered within sublineage IV and V, respectively. These sublineages emerged in late 1990s and they quickly became the most common sublineages found worldwide ${ }^{12,24,34}$.

As of 2011, a reemergence of G3P[8] has been observed in Brazil, replacing the G2P[4] predominance ${ }^{4,22}$. An increase in G3P[8] frequency after 2011 was also observed in other South American countries ${ }^{25}$. In the present study, an increase in the prevalence of G3P[8] in Tocantins State was recorded between 2013 and 2015. Reemergence of G3P[6] and G3P[8] was previously reported in Northern Brazil (Belem) in 2011 and $2012^{26}$. Recently, the emergence of a novel equine-like G3P[8] DS-1-like inter-genogroup reassortant strain was reported worldwide, including in Brazil $^{19,27}$. Equine-like G3P[8] DS-1-like was first identified in Brazil in March, 2015 in the city of Foz do Iguaçu, Southern region, and rapidly spread across the country displaying a potential to replace G3P[8] Wa-like strains ${ }^{19}$. All ten Brazilian G3P[8] strains detected in the present study exhibited the conserved Wa-like backbone gene constellation and intergenogroup reassortants were not observed. This corroborated the hypothesis that the G3P[8] Wa-like strain (wild-type) was the predominant G3 strain circulating in Brazil before $2015^{19}$.

A global emergence of G12P[8] genotype has been reported recently ${ }^{8,28}$. In Brazil, a peak of G12P $[8]$ detection was observed in 2014 and 2015, starting at the beginning of June, 2014 and coinciding with the period when the FIFA Football World Cup was held in this country ${ }^{4,7,8}$. This survey highlights the ongoing G12P[8] dominance in Brazil during this period. The genetic constellation of G12P[8] study strains was consistent with the clonal spread of a single strain belonging to the Wa-like backbone, as previously reported ${ }^{8,25}$. VP7 sequence analysis showed that the Brazilian RVA G12P[8] and G12P[4] strains that we detected clustered within lineage III together with contemporary G12P[8] prototype strains circulating between 2009 and 2015. The G12-III lineage is linked to the global scatter of RVA genotype G12 worldwide ${ }^{8,28}$. In agreement with previous investigations, $\mathrm{P}[8]-3$ is the unique $\mathrm{P}[8]$ lineage circulating in Brazil ${ }^{8,13,23}$. Since 2003, virtually all circulating $\mathrm{P}[8]$ strains belong to lineage $\mathrm{III}^{28,29}$. Unlike G12P[8] Wa-like, G12P[4] DS-1-like strains are sporadically detected and few investigations have analyzed their genetic backbone ${ }^{30}$. The lack of inferences obtained from the phylogenetic analyses reflects the scarcity of data on G12P[4] DS-1-like strains. Explanations on why that particular strain does not remain in circulation are unknown. Reassortment may impose fitness costs if it results in the unlinking of genes and/or proteins that have accumulated compensatory and coadapted mutations $\mathrm{s}^{31}$.

All G8P[4] study strains were identified in 2010, suggesting a local restricted circulation and corroborating the sporadic pattern of G8 strains associated with acute gastroenteritis in the Brazilian population ${ }^{23,32}$. G8 strains have the ability to reassort with RVA strains ecologically suitable to the human gut, including P[4], P[6] and P[8] specificity ${ }^{33}$. However, they do not remain in circulation, suggesting that these strains may not achieve the fitness required to become a successful human pathogen in Brazil, contrary to what is observed in Africa ${ }^{34}$. In the G8P[4] DS-1-like strains detected in India, a possible origin derived from multiple reassortment events between artiodactyls, ruminant and human RVA has been suggested ${ }^{35}$. On the other hand, genetic investigations conducted with G8P[4] DS-1-like strains detected in Italy, Germany and Brazil showed no evidence of recent zoonotic reassortment events $^{23,36,37}$. The genetic analysis of the Brazilian G8P[4] strains detected in Tocantins State has also shown that they do not have a recent zoonotic origin.

Our investigation detected one G1P[8] strain, identified in 2014. The sample was collected from a 3-month-old female with unknown RVA vaccination status. The G1P[8] strain continues to circulate after introduction of the RVA vaccines, as observed in previous studies conducted in Brazil $^{6,7,22}$, as well as globally ${ }^{11,25}$. Vaccine coverage in 
the Northern region is historically lower in comparison with other regions of the country ${ }^{38}$, and RVA vaccination coverage is not an exception ${ }^{3}$. It is worth mentioning that immunization rates in Northern Brazil tend to be lower, either by geographical dispersion, inadequate cold chain capacity, insufficient information and education in several levels of management ${ }^{3}$. Rotarix ${ }^{\mathrm{TM}}$ vaccine coverage in the Northern region in 2014 was lower $(84.1 \%)$ than the national coverage $(93.4 \%)^{39}$. Tocantins State almost reached the national coverage goal (91.9\%), indicating that the common difficulties faced in routine immunizationinthe Northern region does not seem to apply to this particular surveyed area. The Brazilian TO-237 G1P[8] strain was closely related to the RV1 Rotarix ${ }^{\mathrm{TM}}$ strain and to the P[8]-3 lineage (non-vaccine lineage) intheir VP7 and VP4 genome segments, respectively. The other VP1-VP3, VP6 and NSP1-NSP5 genome segments of Brazilian TO-237 G1P[8] strain were closely related to circulating strains belonging to the Wa-like constellation collected worldwide. Based on RVA classical reassortment events and the lack of vaccine medical records of our patient, we were not able to determine the true origin of this TO-237 G1P[8] strain. The effect of universal mass vaccination with RVA vaccines on circulating G1P[8] strains has been intensively investigated over the years ${ }^{13,40}$, highlighting the significance of this particular concern.

\section{CONCLUSION}

In conclusion, our investigation summarizes six years of regional surveillance of RVA diversity in Northern Brazil and presents the first whole-genome data of RVA strains detected in Tocantins State. This provides the basis for monitoring variations in the genetic composition of RVA in this region. In Tocantins State, the same diversity of RVA strains circulating in other Brazilian regions was identified, suggesting that rural and low-income areas do not seem to have a different genotypic distribution compared to other parts of the country. Our findings also contribute to the knowledge of RVA genetic diversity and evolution in a global perspective.

\section{ACKNOWLEDGMENTS}

We thank Luciano Monteiro da Silva for his support. We also thank the MP Biomedicals Inc and General Coordination of Public Health Laboratories of the Strategic Articulation Department, Health Surveillance Secretariat of the Ministry of Health (CGLAB/DAEVS/SVS-MS) for the donation of reagents for this project.

\section{AUTHORS' CONTRIBUTIONS}

MSS, AL and ACC conceived the study; MSS, EL, ECS, $\mathrm{ED}, \mathrm{AL}$ and ACC designed the study protocol; FAPM, RB, VSM, RMA, ELLA and SSW participated in the conduct of the study, collection and screening of the specimens; VSM, SSW and ACC performed the deep-sequencing assays; EL, XD, ED and ACC analyzed the big data; MSS and $\mathrm{AL}$ performed the phylogenetic analysis; MSS, EL, ECS, AL and ACC analyzed and interpreted the data; ED, $\mathrm{AL}$ and ACC supervised the study; MSS and AL drafted the manuscript; All authors critically revised the manuscript for intellectual content and approved the final version. MSS and $\mathrm{AL}$ are guarantors of the paper.

\section{FUNDING}

AL is funded by FAPESP No 2015/12944-9; ACC by FAPESP $\mathrm{N}^{\circ} 2017 / 00021-9$; VSM by FAPESP №2019/21706-5; MSS by CNPq No430181/2018-3; EL by CNPq No302677/2019-4.

\section{CONFLICT OF INTERESTS}

The authors declare that the study did not receive any commercial or financial support that could be interpreted as a conflict of interest.

\section{REFERENCES}

1. Troeger C, Khalil IA, Rao PC, Cao S, Blacker BF, Ahmed T, et al. Rotavirus vaccination and the global burden of Rotavirus diarrhea among children younger than 5 years. JAMA Pediatr. 2018;172:958-65

2. Roczo-Farkas S, Kirkwood CD, Bines JE, Australian Rotavirus Surveillance Group. Australian Rotavirus Surveillance Program annual report, 2015. Commun Dis Intell Q Rep. 2016;40:E527-38.

3. Flannery B, Samad S, de Moraes JC, Tate JE, Danovaro-Holliday MC, de Oliveira LH, et al. Uptake of oral rotavirus vaccine and timeliness of routine immunization in Brazil's National Immunization Program. Vaccine. 2013;31:1523-8.

4. Carvalho-Costa FA, de Assis RM, Fialho AM, Araújo IT, Silva MF, Gómez MM, et al. The evolving epidemiology of rotavirus A infection in Brazil a decade after the introduction of universal vaccination with Rotarix ${ }^{\circledR}$. BMC Pediatr. 2019;19:42.

5. Matthijnssens J, Ciarlet M, Heiman E, Arijs I, Delbeke T, McDonald SM, et al. Full genome-based classification of rotaviruses reveals a common origin between human Wa-Like and porcine rotavirus strains and human DS-1-like and bovine rotavirus strains. J Virol. 2008;82:3204-19. 
6. Bányai K, László B, Duque J, Steele AD, Nelson EA, Gentsch JR, et al. Systematic review of regional and temporal trends in global rotavirus strain diversity in the pre rotavirus vaccine era: insights for understanding the impact of rotavirus vaccination programs. Vaccine. 2012;30 Suppl 1:A122-30.

7. Luchs A, Cilli A, Morillo SG, Gregório DS, de Souza KA, Vieira HR, et al. Detection of the emerging rotavirus G12P[8] genotype at high frequency in brazil in 2014: Successive replacement of predominant strains after vaccine introduction. Acta Trop. 2016;156:87-94.

8. da Silva MF, Fumian TM, de Assis RM, Fialho AM, CarvalhoCosta FA, da Silva Ribeiro de Andrade J, et al. VP7 and VP8* genetic characterization of group A rotavirus genotype G12P[8]: Emergence and spreading in the Eastern Brazilian coast in 2014. J Med Virol. 2017;89:64-70.

9. Matthijnssens J, Ciarlet M, Rahman M, Attoui H, Bányai K, Estes MK, et al. Recommendations for the classification of group A rotaviruses using all 11 genomic RNA segments. Arch Virol. 2008;153:1621-9.

10. Wandera EA, Komoto S, Mohammad S, Ide T, Bundi M, Nyangao $\mathrm{J}$, et al. Genomic characterization of uncommon human G3P[6] rotavirus strains that have emerged in Kenya after rotavirus vaccine introduction, and pre-vaccine human G8P[4] rotavirus strains. Infect Genet Evol. 2019;68:231-48.

11. Dóró R, László B, Martella V, Leshem E, Gentsch J, Parashar U, et al. Review of global rotavirus strain prevalence data from six years post vaccine licensure surveillance: is there evidence of strain selection from vaccine pressure? Infect Genet Evol. 2014;28:446-61.

12. Gómez MM, Carvalho-Costa FA, Volotão Ede M, Rose TL, da Silva MF, Fialho AM, et al. Prevalence and genomic characterization of G2P[4] group A rotavirus strains during monovalent vaccine introduction in Brazil. Infect Genet Evol. 2014;28:486-94.

13. da Silva MF, Rose TL, Gómez MM, Carvalho-Costa FA, Fialho AM, de Assis RM, et al. G1P[8] species A rotavirus over 27 years-pre- and post-vaccination eras-in Brazil: full genomic constellation analysis and no evidence for selection pressure by Rotarix ${ }^{\circledR}$ vaccine. Infect Genet Evol. 2015;30:206-18.

14. Moore NE, Wang J, Hewitt J, Croucher D, Williamson DA, Paine S, et al. Metagenomic analysis of viruses in feces from unsolved outbreaks of gastroenteritis in humans. J Clin Microbiol. 2015;53:15-21.

15. Deng X, Naccache SN, Ng T, Federman S, Li L, Chiu CY, et al. An ensemble strategy that significantly improves de novo assembly of microbial genomes from metagenomic next-generation sequencing data. Nucleic Acids Res. 2015;43:e46.

16. Virus Pathogen Resource. [cited 2020 Nov 27]. Available from: https://www.viprbrc.org

17. Thompson JD, Higgins DG, Gibson TJ. CLUSTAL W: improving the sensitivity of progressive multiple sequence alignment through sequence weighting, position-specific gap penalties and weight matrix choice. Nucleic Acids Res. 1994;22:467380.

18. Kumar S, Stecher G, Tamura K. MEGA7: Molecular Evolutionary Genetics Analysis Version 7.0 for bigger datasets. Mol Biol Evol. 2016;33:1870-4.

19. Luchs A, da Costa AC, Cilli A, Komninakis SC, Carmona RC, Boen L, et al. Spread of the emerging equine-like G3P[8] DS-1-like genetic backbone rotavirus strain in Brazil and identification of potential genetic variants. J Gen Virol. 2019;100:7-25.

20. Carvalho-Costa FA, Volotão EM, de Assis RM, Fialho AM, de Andrade JS, Rocha LN, et al. Laboratory-based rotavirus surveillance during the introduction of a vaccination program, Brazil, 2005-2009. Pediatr Infect Dis J. 2011;30 Suppl 1:S35-41.

21. Guerra SF, Fecury PC, Bezerra DA, Lobo PS, Penha Júnior ET, Sousa Júnior E, et al. Emergence of G12P[6] rotavirus strains among hospitalised children with acute gastroenteritis in Belém, Northern Brazil, following introduction of a rotavirus vaccine. Arch Virol. 2019;164:2107-17.

22. Luchs A, Cilli A, Morillo SG, Carmona RC, Timenetsky MC. Rotavirus genotypes circulating in Brazil, 2007-2012: implications for the vaccine program. Rev Inst Med Trop Sao Paulo. 2015;57:305-13

23. Dulgheroff AC, Silva GA, Naveca FG, Oliveira AG, Domingues AL. Diversity of group A rotavirus genes detected in the Triângulo Mineiro region, Minas Gerais, Brazil. Braz J Microbiol. 2016;47:731-40.

24. Giammanco GM, Bonura F, Zeller M, Heylen E, Van Ranst M, Martella V, et al. Evolution of DS-1-like human G2P[4] rotaviruses assessed by complete genome analyses. J Gen Virol. 2014;95:91-109.

25. Stupka JA, Degiuseppe JI, Parra GI, Argentinean National Rotavirus Surveillance Network. Increased frequency of rotavirus G3P[8] and G12P[8] in Argentina during 2008-2009: whole-genome characterization of emerging G12P[8] strains. J Clin Virol. 2012;54:162-7.

26. Soares LS, Guerra SF, Oliveira AD, Santos FS, Menezes EM, Mascarenhas J, Linhares AC. Diversity of rotavirus strains circulating in Northern Brazil after introduction of a rotavirus vaccine: high prevalence of G3P[6] genotype. J Med Virol. 2014;86:1065-72

27. Arana A, Montes M, Jere KC, Alkorta M, Iturriza-Gómara M, Cilla G. Emergence and spread of G3P[8] rotaviruses possessing an equine-like VP7 and a DS-1-like genetic backbone in the Basque Country (North of Spain), 2015. Infect Genet Evol. 2016;44:137-44.

28. Mijatovic-Rustempasic S, Teel EN, Kerin TK, Hull JJ, Roy S, Weinberg GA, et al. Genetic analysis of G12P[8] rotaviruses detected in the largest U.S. G12 genotype outbreak on record. Infect Genet Evol. 2014;21:214-9. 
29. Damanka SA, Agbemabiese CA, Dennis FE, Lartey BL, Adiku TK, Enweronu-Laryea CC, et al. Genetic analysis of Ghanaian G1P[8] and G9P[8] rotavirus A strains reveals the impact of P[8] VP4 gene polymorphism on P-genotyping. PLoS One. 2019;14:e0218790.

30. Jere KC, Mlera L, O'Neill HG, Potgieter AC, Page NA, Seheri ML, et al. Whole genome analyses of African G2, G8, G9, and G12 rotavirus strains using sequence-independent amplification and 454 ${ }^{\circledR}$ pyrosequencing. J Med Virol. 2011;83:2018-42.

31. Zhang S, McDonald PW, Thompson TA, Dennis AF, Akopov A, Kirkness EF, et al. Analysis of human rotaviruses from a single location over an 18-year time span suggests that protein coadaption influences gene constellations. J Virol. 2014;88:9842-63.

32. Luchs A, Timenetsky MD. G8P[6] rotaviruses isolated from Amerindian children in Mato Grosso do Sul, Brazil, during 2009: close relationship of the $\mathrm{G}$ and $\mathrm{P}$ genes with those of bovine and bat strains. J Gen Virol. 2014;95:627-41.

33. Page N, Esona M, Seheri M, Nyangao J, Bos P, Mwenda J, et al. Characterization of genotype G8 strains from Malawi, Kenya, and South Africa. J Med Virol. 2010;82:2073-81.

34. Esona MD, Geyer A, Page N, Trabelsi A, Fodha I, Aminu M, et al. Genomic characterization of human rotavirus G8 strains from the African rotavirus network: relationship to animal rotaviruses. J Med Virol. 2009;81:937-51.
35. Mukherjee A, Mullick S, Deb AK, Panda S, Chawla-Sarkar M. First report of human rotavirus G8P[4] gastroenteritis in India: evidence of ruminants-to-human zoonotic transmission. J Med Virol. 2013;85:537-45.

36. Pietsch C, Petersen L, Patzer L, Liebert UG. Molecular characteristics of German G8P[4] rotavirus strain GER1H-09 suggest that a genotyping and subclassification update is required for G8. J Clin Microbiol. 2009;47:3569-76.

37. Ianiro G, Delogu R, Bonomo P, Castiglia P, Ruggeri FM, Fiore L. Molecular characterization of human G8P[4] rotavirus strains in Italy: proposal of a more complete subclassification of the G8 genotype in three major lineages. Infect Genet Evol. 2014;21:129-33.

38. Arroyo LH, Ramos AC, Yamamura M, Weiller TH, Crispim JA, Cartagena-Ramos D, et al. Áreas com queda da cobertura vacinal para BCG, poliomielite e tríplice viral no Brasil (20062016): mapas da heterogeneidade regional. Cad Saude Publica. 2020;36:e00015619.

39. Brasil. Ministério da Saúde. DATASUS: informações de saúde (TABNET). [cited 2020 Nov 27]. Available from: http://tabnet. datasus.gov.br

40. Zeller M, Heylen E, Tamim S, McAllen JK, Kirkness EF, Akopov A, et al. Comparative analysis of the Rotari ${ }^{\mathrm{TM}}$ vaccine strain and $\mathrm{G} 1 \mathrm{P}[8]$ rotaviruses detected before and after vaccine introduction in Belgium. PeerJ. 2017;5:e2733.

\section{SUPPLEMENTARY MATERIAL}

Table S1 - Genotype constellation of all 107 Brazilian rotavirus A (RVA) strains detected in the present study. The sample name is indicated with TO (Tocantins) followed by a correspondent number. Genotypes represented in green and red are associated with the Wa-like and DS-1-like RVA backbones, respectively.

\begin{tabular}{|c|c|c|c|c|c|c|c|c|c|c|c|}
\hline Sample & VP1 & VP2 & VP3 & VP4 & VP6 & VP7 & NSP1 & NSP2 & NSP3 & NSP4 & NSP5 \\
\hline TO-1 & $\mathrm{R} 1$ & C1 & M1 & $\mathrm{P}[8]$ & 11 & $\mathrm{G} 12$ & $\mathrm{~A} 1$ & $\mathrm{~T} 1$ & N1 & $\mathrm{E} 1$ & $\mathrm{H} 1$ \\
\hline TO-2 & R2 & C2 & M2 & $\mathrm{P}[4]$ & 12 & G2 & A2 & T2 & N2 & E2 & $\mathrm{H} 2$ \\
\hline TO-3 & $\mathrm{R} 1$ & C1 & M1 & $\mathrm{P}[8]$ & 11 & $\mathrm{G} 12$ & $\mathrm{~A} 1$ & $\mathrm{~T} 1$ & $\mathrm{~N} 1$ & E1 & $\mathrm{H} 1$ \\
\hline TO-4 & $\mathrm{R} 1$ & C1 & M1 & $\mathrm{P}[8]$ & I1 & G12 & $\mathrm{A} 1$ & T1 & $\mathrm{N} 1$ & E1 & $\mathrm{H} 1$ \\
\hline TO-5 & R1 & C1 & M1 & $\mathrm{P}[8]$ & 11 & G12 & $\mathrm{A} 1$ & T1 & $\mathrm{N} 1$ & E1 & $\mathrm{H} 1$ \\
\hline TO-6 & $\mathrm{R} 1$ & C1 & M1 & $\mathrm{P}[8]$ & 11 & $\mathrm{G} 12$ & $\mathrm{~A} 1$ & $\mathrm{~T} 1$ & $\mathrm{~N} 1$ & E1 & $\mathrm{H} 1$ \\
\hline TO-7 & $\mathrm{R} 1$ & C1 & M1 & $\mathrm{P}[8]$ & I1 & G12 & $\mathrm{A} 1$ & T1 & $\mathrm{N} 1$ & E1 & $\mathrm{H} 1$ \\
\hline TO-8 & $\mathrm{R} 1$ & C1 & M1 & $\mathrm{P}[8]$ & 11 & $\mathrm{G} 12$ & $\mathrm{~A} 1$ & $\mathrm{~T} 1$ & $\mathrm{~N} 1$ & E1 & $\mathrm{H} 1$ \\
\hline TO-9 & $\mathrm{R} 1$ & C1 & M1 & $\mathrm{P}[8]$ & 11 & $\mathrm{G} 12$ & $\mathrm{~A} 1$ & $\mathrm{~T} 1$ & N1 & E1 & $\mathrm{H} 1$ \\
\hline TO-10 & $\mathrm{R} 1$ & $\mathrm{C} 1$ & M1 & $\mathrm{P}[8]$ & 11 & G12 & $\mathrm{A} 1$ & $\mathrm{~T} 1$ & N1 & E1 & $\mathrm{H} 1$ \\
\hline TO-11 & $\mathrm{R} 1$ & C1 & M1 & $\mathrm{P}[8]$ & 11 & G12 & $\mathrm{A} 1$ & T1 & $\mathrm{N} 1$ & E1 & $\mathrm{H} 1$ \\
\hline TO-12 & $\mathrm{R} 1$ & $\mathrm{C} 1$ & M1 & $\mathrm{P}[8]$ & 11 & G12 & $\mathrm{A} 1$ & $\mathrm{~T} 1$ & N1 & E1 & $\mathrm{H} 1$ \\
\hline TO-13 & $\mathrm{R} 1$ & $\mathrm{C} 1$ & M1 & $\mathrm{P}[8]$ & 11 & G12 & $\mathrm{A} 1$ & $\mathrm{~T} 1$ & N1 & E1 & $\mathrm{H} 1$ \\
\hline TO-14 & $\mathrm{R} 1$ & $\mathrm{C} 1$ & M1 & $\mathrm{P}[8]$ & 11 & G12 & $\mathrm{A} 1$ & $\mathrm{~T} 1$ & N1 & E1 & $\mathrm{H} 1$ \\
\hline TO-16 & $\mathrm{R} 1$ & $\mathrm{C} 1$ & M1 & $\mathrm{P}[8]$ & 11 & G12 & $\mathrm{A} 1$ & $\mathrm{~T} 1$ & N1 & E1 & $\mathrm{H} 1$ \\
\hline TO-17 & $\mathrm{R} 1$ & C1 & M1 & $\mathrm{P}[8]$ & 11 & G12 & $\mathrm{A} 1$ & T1 & $\mathrm{N} 1$ & E1 & $\mathrm{H} 1$ \\
\hline TO-18 & $\mathrm{R} 1$ & C1 & M1 & $\mathrm{P}[8]$ & 11 & G12 & $\mathrm{A} 1$ & T1 & $\mathrm{N} 1$ & E1 & $\mathrm{H} 1$ \\
\hline TO-19 & R1 & C1 & M1 & $\mathrm{P}[8]$ & 11 & G12 & $\mathrm{A} 1$ & T1 & $\mathrm{N} 1$ & E1 & $\mathrm{H} 1$ \\
\hline TO-22 & R2 & C2 & M2 & $\mathrm{P}[4]$ & 12 & G2 & A2 & T2 & N2 & E2 & $\mathrm{H} 2$ \\
\hline
\end{tabular}


Table S1 - Genotype constellation of all 107 Brazilian rotavirus A (RVA) strains detected in the present study. The sample name is indicated with TO (Tocantins) followed by a correspondent number. Genotypes represented in green and red are associated with the Wa-like and DS-1-like RVA backbones, respectively (cont.).

\begin{tabular}{|c|c|c|c|c|c|c|c|c|c|c|c|}
\hline Sample & VP1 & VP2 & VP3 & VP4 & VP6 & VP7 & NSP1 & NSP2 & NSP3 & NSP4 & NSP5 \\
\hline TO-23 & R1 & C1 & M1 & $\mathrm{P}[8]$ & 11 & G12 & $\mathrm{A} 1$ & T1 & $\mathrm{N} 1$ & E1 & $\mathrm{H} 1$ \\
\hline TO-28 & $\mathrm{R} 1$ & C1 & M1 & $\mathrm{P}[8]$ & 11 & G12 & $\mathrm{A} 1$ & T1 & N1 & E1 & $\mathrm{H} 1$ \\
\hline TO-29 & R1 & C1 & M1 & $\mathrm{P}[8]$ & 11 & G12 & $\mathrm{A} 1$ & T1 & N1 & E1 & $\mathrm{H} 1$ \\
\hline TO-30 & $\mathrm{R} 1$ & $\mathrm{C} 1$ & M1 & $\mathrm{P}[8]$ & 11 & G12 & $\mathrm{A} 1$ & T1 & N1 & E1 & $\mathrm{H} 1$ \\
\hline TO-33 & $\mathrm{R} 1$ & C1 & M1 & $\mathrm{P}[8]$ & 11 & G12 & $\mathrm{A} 1$ & T1 & $\mathrm{N} 1$ & E1 & $\mathrm{H} 1$ \\
\hline TO-34 & $\mathrm{R} 1$ & C1 & M1 & $\mathrm{P}[8]$ & 11 & G12 & $\mathrm{A} 1$ & T1 & $\mathrm{N} 1$ & E1 & $\mathrm{H} 1$ \\
\hline TO-35 & $\mathrm{R} 1$ & C1 & M1 & $\mathrm{P}[8]$ & 11 & G12 & A1 & T1 & $\mathrm{N} 1$ & E1 & $\mathrm{H} 1$ \\
\hline TO-36 & $\mathrm{R} 1$ & $\mathrm{C} 1$ & $\mathrm{M} 1$ & $\mathrm{P}[8]$ & 11 & G12 & $\mathrm{A} 1$ & T1 & N1 & E1 & $\mathrm{H} 1$ \\
\hline TO-37 & $\mathrm{R} 1$ & C1 & M1 & $\mathrm{P}[8]$ & 11 & G12 & $\mathrm{A} 1$ & $\mathrm{~T} 1$ & $\mathrm{~N} 1$ & E1 & $\mathrm{H} 1$ \\
\hline TO-38 & $\mathrm{R} 1$ & C1 & M1 & $\mathrm{P}[8]$ & 11 & G12 & $\mathrm{A} 1$ & T1 & N1 & E1 & $\mathrm{H} 1$ \\
\hline TO-39 & R2 & C2 & M2 & $\mathrm{P}[4]$ & 12 & G2 & A2 & T2 & N2 & E2 & $\mathrm{H} 2$ \\
\hline TO-40 & R1 & C1 & M1 & $\mathrm{P}[8]$ & 11 & G12 & $\mathrm{A} 1$ & T1 & $\mathrm{N} 1$ & E1 & $\mathrm{H} 1$ \\
\hline TO-41 & $\mathrm{R} 1$ & C1 & M1 & $\mathrm{P}[8]$ & 11 & G12 & $\mathrm{A} 1$ & T1 & N1 & E1 & $\mathrm{H} 1$ \\
\hline TO-42 & $\mathrm{R} 1$ & C1 & M1 & $\mathrm{P}[8]$ & 11 & G3 & $\mathrm{A} 1$ & T1 & N1 & E1 & $\mathrm{H} 1$ \\
\hline TO-45 & $\mathrm{R} 1$ & C1 & M1 & $\mathrm{P}[8]$ & 11 & G12 & $\mathrm{A} 1$ & T1 & N1 & E1 & $\mathrm{H} 1$ \\
\hline TO-46 & $\mathrm{R} 1$ & $\mathrm{C} 1$ & M1 & $\mathrm{P}[8]$ & 11 & G12 & A1 & T1 & N1 & E1 & $\mathrm{H} 1$ \\
\hline ТО-48 & $\mathrm{R} 1$ & C1 & M1 & $\mathrm{P}[4]$ & 11 & G12 & $\mathrm{A} 1$ & T1 & N1 & E1 & $\mathrm{H} 1$ \\
\hline TO-49 & R1 & C1 & M1 & $\mathrm{P}[8]$ & 11 & G12 & A1 & T1 & $\mathrm{N} 1$ & E1 & $\mathrm{H} 1$ \\
\hline TO-50 & $\mathrm{R} 1$ & C1 & M1 & $\mathrm{P}[8]$ & 11 & G12 & $\mathrm{A} 1$ & T1 & N1 & E1 & $\mathrm{H} 1$ \\
\hline TO-51 & $\mathrm{R} 1$ & $\mathrm{C} 1$ & $\mathrm{M} 1$ & $\mathrm{P}[8]$ & 11 & G12 & $\mathrm{A} 1$ & T1 & N1 & E1 & $\mathrm{H} 1$ \\
\hline TO-55 & R1 & C1 & M1 & $\mathrm{P}[8]$ & 11 & G3 & $\mathrm{A} 1$ & $\mathrm{~T} 1$ & $\mathrm{~N} 1$ & E1 & $\mathrm{H} 1$ \\
\hline TO-58 & R2 & C2 & M2 & $\mathrm{P}[4]$ & 12 & G2 & A2 & T2 & N2 & E2 & $\mathrm{H} 2$ \\
\hline TO-59 & $\mathrm{R} 1$ & C1 & M1 & $\mathrm{P}[8]$ & 11 & G12 & $\mathrm{A} 1$ & T1 & N1 & E1 & $\mathrm{H} 1$ \\
\hline TO-60 & $\mathrm{R} 1$ & C1 & M1 & $\mathrm{P}[8]$ & 11 & G12 & $\mathrm{A} 1$ & $\mathrm{~T} 1$ & N1 & E1 & $\mathrm{H} 1$ \\
\hline TO-61 & $\mathrm{R} 1$ & $\mathrm{C} 1$ & M1 & $\mathrm{P}[8]$ & 11 & G12 & $\mathrm{A} 1$ & $\mathrm{~T} 1$ & $\mathrm{~N} 1$ & E1 & $\mathrm{H} 1$ \\
\hline TO-62 & $\mathrm{R} 1$ & C1 & M1 & $\mathrm{P}[8]$ & 11 & G12 & $\mathrm{A} 1$ & T1 & N1 & E1 & $\mathrm{H} 1$ \\
\hline TO-63 & $\mathrm{R} 1$ & $\mathrm{C} 1$ & $\mathrm{M} 1$ & $\mathrm{P}[8]$ & 11 & G12 & $\mathrm{A} 1$ & $\mathrm{~T} 1$ & $\mathrm{~N} 1$ & E1 & $\mathrm{H} 1$ \\
\hline TO-64 & $\mathrm{R} 1$ & $\mathrm{C} 1$ & $\mathrm{M} 1$ & $\mathrm{P}[8]$ & 11 & G12 & $\mathrm{A} 1$ & $\mathrm{~T} 1$ & $\mathrm{~N} 1$ & E1 & $\mathrm{H} 1$ \\
\hline TO-65 & $\mathrm{R} 1$ & $\mathrm{C} 1$ & M1 & $\mathrm{P}[8]$ & 11 & G12 & $\mathrm{A} 1$ & $\mathrm{~T} 1$ & $\mathrm{~N} 1$ & E1 & $\mathrm{H} 1$ \\
\hline TO-66 & $\mathrm{R} 1$ & $\mathrm{C} 1$ & $\mathrm{M} 1$ & $\mathrm{P}[8]$ & 11 & G12 & $\mathrm{A} 1$ & $\mathrm{~T} 1$ & $\mathrm{~N} 1$ & E1 & $\mathrm{H} 1$ \\
\hline TO-67 & $\mathrm{R} 1$ & C1 & M1 & $\mathrm{P}[8]$ & 11 & G12 & $\mathrm{A} 1$ & T1 & $\mathrm{N} 1$ & E1 & $\mathrm{H} 1$ \\
\hline TO-69 & $\mathrm{R} 1$ & C1 & M1 & $\mathrm{P}[8]$ & 11 & G12 & $\mathrm{A} 1$ & T1 & $\mathrm{N} 1$ & E1 & $\mathrm{H} 1$ \\
\hline TO-70 & $\mathrm{R} 1$ & $\mathrm{C} 1$ & $\mathrm{M} 1$ & $\mathrm{P}[8]$ & 11 & G12 & $\mathrm{A} 1$ & $\mathrm{~T} 1$ & $\mathrm{~N} 1$ & $\mathrm{E} 1$ & $\mathrm{H} 1$ \\
\hline TO-71 & $\mathrm{R} 1$ & $\mathrm{C} 1$ & $\mathrm{M} 1$ & $\mathrm{P}[8]$ & 11 & $\mathrm{G} 12$ & $\mathrm{~A} 1$ & $\mathrm{~T} 1$ & $\mathrm{~N} 1$ & E1 & $\mathrm{H} 1$ \\
\hline TO-72 & $\mathrm{R} 1$ & $\mathrm{C} 1$ & M1 & $\mathrm{P}[8]$ & 11 & G12 & $\mathrm{A} 1$ & $\mathrm{~T} 1$ & $\mathrm{~N} 1$ & E1 & $\mathrm{H} 1$ \\
\hline TO-73 & R2 & C2 & M2 & $\mathrm{P}[4]$ & 12 & G8 & A2 & T2 & N2 & E2 & H2 \\
\hline TO-74 & $\mathrm{R} 1$ & $\mathrm{C} 1$ & M1 & $\mathrm{P}[8]$ & 11 & G12 & $\mathrm{A} 1$ & $\mathrm{~T} 1$ & $\mathrm{~N} 1$ & $\mathrm{E} 1$ & $\mathrm{H} 1$ \\
\hline TO-75 & $\mathrm{R} 2$ & C2 & M2 & $\mathrm{P}[4]$ & 12 & G12 & A2 & T2 & N2 & C2 & $\mathrm{H} 2$ \\
\hline TO-77 & $\mathrm{R} 1$ & C1 & M1 & $\mathrm{P}[8]$ & I1 & G12 & $\mathrm{A} 1$ & T1 & N1 & E1 & $\mathrm{H} 1$ \\
\hline TO-78 & $\mathrm{R} 1$ & $\mathrm{C} 1$ & M1 & $\mathrm{P}[8]$ & 11 & G12 & $\mathrm{A} 1$ & $\mathrm{~T} 1$ & $\mathrm{~N} 1$ & $\mathrm{E} 1$ & $\mathrm{H} 1$ \\
\hline TO-79 & $\mathrm{R} 1$ & $\mathrm{C} 1$ & $\mathrm{M} 1$ & $\mathrm{P}[8]$ & 11 & G12 & $\mathrm{A} 1$ & $\mathrm{~T} 1$ & $\mathrm{~N} 1$ & E1 & $\mathrm{H} 1$ \\
\hline TO-80 & $\mathrm{R} 1$ & $\mathrm{C} 1$ & $\mathrm{M} 1$ & $\mathrm{P}[8]$ & 11 & $\mathrm{G} 12$ & $\mathrm{~A} 1$ & $\mathrm{~T} 1$ & $\mathrm{~N} 1$ & E1 & $\mathrm{H} 1$ \\
\hline TO-81 & $\mathrm{R} 1$ & C1 & M1 & $\mathrm{P}[8]$ & 11 & $\mathrm{G} 12$ & $\mathrm{~A} 1$ & $\mathrm{~T} 1$ & $\mathrm{~N} 1$ & E1 & $\mathrm{H} 1$ \\
\hline TO-82 & $\mathrm{R} 1$ & $\mathrm{C} 1$ & $\mathrm{M} 1$ & $\mathrm{P}[8]$ & 11 & $\mathrm{G} 12$ & $\mathrm{~A} 1$ & $\mathrm{~T} 1$ & $\mathrm{~N} 1$ & E1 & $\mathrm{H} 1$ \\
\hline TO-83 & $\mathrm{R} 1$ & C1 & M1 & $\mathrm{P}[8]$ & $\mid 1$ & G12 & $\mathrm{A} 1$ & T1 & N1 & E1 & $\mathrm{H} 1$ \\
\hline TO-84 & $\mathrm{R} 1$ & $\mathrm{C} 1$ & $\mathrm{M} 1$ & $\mathrm{P}[8]$ & 11 & G12 & $\mathrm{A} 1$ & $\mathrm{~T} 1$ & $\mathrm{~N} 1$ & $\mathrm{E} 1$ & $\mathrm{H} 1$ \\
\hline TO-85 & $\mathrm{R} 1$ & $\mathrm{C} 1$ & $\mathrm{M} 1$ & $\mathrm{P}[8]$ & 11 & $\mathrm{G} 12$ & $\mathrm{~A} 1$ & $\mathrm{~T} 1$ & $\mathrm{~N} 1$ & E1 & $\mathrm{H} 1$ \\
\hline TO-86 & $\mathrm{R} 1$ & $\mathrm{C} 1$ & M1 & $\mathrm{P}[8]$ & 11 & G12 & $\mathrm{A} 1$ & $\mathrm{~T} 1$ & $\mathrm{~N} 1$ & E1 & $\mathrm{H} 1$ \\
\hline TO-87 & $\mathrm{R} 1$ & $\mathrm{C} 1$ & M1 & $\mathrm{P}[8]$ & 11 & $\mathrm{G} 12$ & $\mathrm{~A} 1$ & T1 & N1 & E1 & $\mathrm{H} 1$ \\
\hline TO-88 & $\mathrm{R} 1$ & C1 & M1 & $\mathrm{P}[8]$ & 11 & $\mathrm{G} 12$ & $\mathrm{~A} 1$ & $\mathrm{~T} 1$ & $\mathrm{~N} 1$ & E1 & $\mathrm{H} 1$ \\
\hline
\end{tabular}


Table S1 - Genotype constellation of all 107 Brazilian rotavirus A (RVA) strains detected in the present study. The sample name is indicated with TO (Tocantins) followed by a correspondent number. Genotypes represented in green and red are associated with the Wa-like and DS-1-like RVA backbones, respectively (cont.).

\begin{tabular}{|c|c|c|c|c|c|c|c|c|c|c|c|}
\hline Sample & VP1 & VP2 & VP3 & VP4 & VP6 & VP7 & NSP1 & NSP2 & NSP3 & NSP4 & NSP5 \\
\hline TO-89 & $\mathrm{R} 1$ & $\mathrm{C} 1$ & M1 & $\mathrm{P}[8]$ & 11 & G12 & A1 & T1 & N1 & E1 & $\mathrm{H} 1$ \\
\hline ТО-90 & $\mathrm{R} 1$ & $\mathrm{C} 1$ & M1 & $\mathrm{P}[8]$ & 11 & G12 & $\mathrm{A} 1$ & $\mathrm{~T} 1$ & N1 & E1 & $\mathrm{H} 1$ \\
\hline ТО-91 & $\mathrm{R} 1$ & $\mathrm{C} 1$ & M1 & $\mathrm{P}[8]$ & 11 & G12 & $\mathrm{A} 1$ & $\mathrm{~T} 1$ & N1 & E1 & $\mathrm{H} 1$ \\
\hline TO-92 & $\mathrm{R} 1$ & $\mathrm{C} 1$ & M1 & $\mathrm{P}[8]$ & 11 & G12 & $\mathrm{A} 1$ & T1 & N1 & $\mathrm{E} 1$ & $\mathrm{H} 1$ \\
\hline ТО-93 & $\mathrm{R} 1$ & $\mathrm{C} 1$ & M1 & $\mathrm{P}[8]$ & 11 & G12 & $\mathrm{A} 1$ & $\mathrm{~T} 1$ & N1 & E1 & $\mathrm{H} 1$ \\
\hline TO-94 & $\mathrm{R} 1$ & $\mathrm{C} 1$ & M1 & $\mathrm{P}[8]$ & 11 & G12 & $\mathrm{A} 1$ & T1 & N1 & E1 & $\mathrm{H} 1$ \\
\hline TO-95 & $\mathrm{R} 2$ & $\mathrm{C} 2$ & M2 & $\mathrm{P}[4]$ & 12 & G2 & $\mathrm{A} 2$ & T2 & N2 & E2 & $\mathrm{H} 2$ \\
\hline TO-105 & $\mathrm{R} 1$ & $\mathrm{C} 1$ & M1 & $\mathrm{P}[8]$ & 11 & G12 & $\mathrm{A} 1$ & $\mathrm{~T} 1$ & N1 & $\mathrm{E} 1$ & $\mathrm{H} 1$ \\
\hline TO-114 & $\mathrm{R} 1$ & $\mathrm{C} 1$ & M1 & $\mathrm{P}[8]$ & 11 & G3 & $\mathrm{A} 1$ & $\mathrm{~T} 1$ & N1 & E1 & $\mathrm{H} 1$ \\
\hline TO-118 & $\mathrm{R} 1$ & $\mathrm{C} 1$ & M1 & $\mathrm{P}[8]$ & 11 & G12 & $\mathrm{A} 1$ & $\mathrm{~T} 1$ & N1 & E1 & $\mathrm{H} 1$ \\
\hline TO-126 & $\mathrm{R} 1$ & $\mathrm{C} 1$ & M1 & $\mathrm{P}[8]$ & 11 & G12 & $\mathrm{A} 1$ & $\mathrm{~T} 1$ & N1 & E1 & $\mathrm{H} 1$ \\
\hline TO-130 & $\mathrm{R} 1$ & $\mathrm{C} 1$ & M1 & $\mathrm{P}[8]$ & 11 & G12 & A1 & $\mathrm{T} 1$ & N1 & E1 & $\mathrm{H} 1$ \\
\hline TO-142 & $\mathrm{R} 1$ & $\mathrm{C} 1$ & M1 & $\mathrm{P}[8]$ & 11 & G12 & $\mathrm{A} 1$ & $\mathrm{~T} 1$ & N1 & E1 & $\mathrm{H} 1$ \\
\hline TO-144 & $\mathrm{R} 1$ & $\mathrm{C} 1$ & M1 & $\mathrm{P}[8]$ & 11 & G12 & $\mathrm{A} 1$ & $\mathrm{~T} 1$ & N1 & E1 & $\mathrm{H} 1$ \\
\hline TO-154 & $\mathrm{R} 1$ & $\mathrm{C} 1$ & M1 & $\mathrm{P}[8]$ & 11 & G3 & $\mathrm{A} 1$ & $\mathrm{~T} 1$ & N1 & E1 & $\mathrm{H} 1$ \\
\hline ТО-162 & $\mathrm{R} 1$ & $\mathrm{C} 1$ & M1 & $\mathrm{P}[8]$ & 11 & G12 & $\mathrm{A} 1$ & $\mathrm{~T} 1$ & N1 & E1 & $\mathrm{H} 1$ \\
\hline TO-167 & $\mathrm{R} 1$ & $\mathrm{C} 1$ & M1 & $\mathrm{P}[8]$ & 11 & G3 & A1 & T1 & N1 & E1 & $\mathrm{H} 1$ \\
\hline TO-173 & $\mathrm{R} 2$ & $\mathrm{C} 2$ & M2 & $\mathrm{P}[4]$ & 12 & G2/G8 & $\mathrm{A} 2$ & T2 & N2 & E2 & $\mathrm{H} 2$ \\
\hline TO-174 & $\mathrm{R} 2$ & $\mathrm{C} 2$ & M2 & $P[4]$ & 12 & G8 & $\mathrm{A} 2$ & T2 & N2 & E2 & $\mathrm{H} 2$ \\
\hline TO-179 & $\mathrm{R} 1$ & $\mathrm{C} 1$ & M1 & $\mathrm{P}[8]$ & 11 & G12 & A1 & $\mathrm{T} 1$ & N1 & E1 & $\mathrm{H} 1$ \\
\hline ТО-181 & $\mathrm{R} 1$ & $\mathrm{C} 1$ & M1 & $\mathrm{P}[8]$ & 11 & G12 & $\mathrm{A} 1$ & $\mathrm{~T} 1$ & N1 & E1 & $\mathrm{H} 1$ \\
\hline TO-182 & $\mathrm{R} 1$ & $\mathrm{C} 1$ & M1 & $\mathrm{P}[8]$ & 11 & G3 & $\mathrm{A} 1$ & $\mathrm{~T} 1$ & N1 & E1 & $\mathrm{H} 1$ \\
\hline TO-186 & $\mathrm{R} 1$ & $\mathrm{C} 1$ & M1 & $\mathrm{P}[8]$ & 11 & G12 & $\mathrm{A} 1$ & $\mathrm{~T} 1$ & N1 & E1 & $\mathrm{H} 1$ \\
\hline ТО-190 & $\mathrm{R} 1$ & $\mathrm{C} 1$ & M1 & $\mathrm{P}[8]$ & 11 & G12 & $\mathrm{A} 1$ & $\mathrm{~T} 1$ & N1 & E1 & $\mathrm{H} 1$ \\
\hline ТО-191 & $\mathrm{R} 1$ & $\mathrm{C} 1$ & M1 & $\mathrm{P}[8]$ & 11 & G3 & $\mathrm{A} 1$ & $\mathrm{~T} 1$ & N1 & E1 & $\mathrm{H} 1$ \\
\hline TO-192 & $\mathrm{R} 1$ & $\mathrm{C} 1$ & M1 & $\mathrm{P}[8]$ & 11 & G12 & $\mathrm{A} 1$ & $\mathrm{~T} 1$ & N1 & E1 & $\mathrm{H} 1$ \\
\hline ТО-196 & $\mathrm{R} 1$ & $\mathrm{C} 1$ & M1 & $\mathrm{P}[8]$ & 11 & G3 & $\mathrm{A} 1$ & $\mathrm{~T} 1$ & N1 & E1 & $\mathrm{H} 1$ \\
\hline TO-197 & $\mathrm{R} 1$ & $\mathrm{C} 1$ & M1 & $\mathrm{P}[8]$ & 11 & G3 & $\mathrm{A} 1$ & T1 & N1 & E1 & $\mathrm{H} 1$ \\
\hline TO-222 & $\mathrm{R} 1$ & $\mathrm{C} 1$ & M1 & $\mathrm{P}[8]$ & 11 & G12 & $\mathrm{A} 1$ & $\mathrm{~T} 1$ & N1 & E1 & $\mathrm{H} 1$ \\
\hline TO-224 & $\mathrm{R} 1$ & $\mathrm{C} 1$ & M1 & $\mathrm{P}[8]$ & 11 & G12 & $\mathrm{A} 1$ & $\mathrm{~T} 1$ & N1 & E1 & $\mathrm{H} 1$ \\
\hline ТО-226 & $\mathrm{R} 1$ & $\mathrm{C} 1$ & M1 & $\mathrm{P}[8]$ & 11 & G12 & $\mathrm{A} 1$ & $\mathrm{~T} 1$ & N1 & E1 & $\mathrm{H} 1$ \\
\hline TO-227 & $\mathrm{R} 1$ & $\mathrm{C} 1$ & M1 & $P[8]$ & 11 & G12 & A1 & $\mathrm{T} 1$ & N1 & E1 & $\mathrm{H} 1$ \\
\hline TO-228 & $\mathrm{R} 2$ & $\mathrm{C} 2$ & M2 & $\mathrm{P}[4]$ & 12 & G2 & $\mathrm{A} 2$ & T2 & N2 & E2 & $\mathrm{H} 2$ \\
\hline ТО-231 & $\mathrm{R} 1$ & $\mathrm{C} 1$ & M1 & $\mathrm{P}[8]$ & 11 & G3 & $\mathrm{A} 1$ & $\mathrm{~T} 1$ & N1 & E1 & $\mathrm{H} 1$ \\
\hline ТО-236 & $\mathrm{R} 1$ & $\mathrm{C} 1$ & M1 & $\mathrm{P}[8]$ & 11 & G12 & $\mathrm{A} 1$ & $\mathrm{~T} 1$ & N1 & $\mathrm{E} 1$ & $\mathrm{H} 1$ \\
\hline TO-237 & $\mathrm{R} 1$ & $\mathrm{C} 1$ & M1 & $\mathrm{P}[8]$ & 11 & $\mathrm{G} 1$ & $\mathrm{~A} 1$ & $\mathrm{~T} 1$ & N1 & E1 & $\mathrm{H} 1$ \\
\hline TO-242 & $\mathrm{R} 1$ & $\mathrm{C} 1$ & M1 & $\mathrm{P}[8]$ & 11 & G12 & $\mathrm{A} 1$ & $\mathrm{~T} 1$ & N1 & $\mathrm{E} 1$ & $\mathrm{H} 1$ \\
\hline TO-243 & $\mathrm{R} 1$ & $\mathrm{C} 1$ & M1 & $\mathrm{P}[8]$ & 11 & G3 & $\mathrm{A} 1$ & T1 & N1 & E1 & $\mathrm{H} 1$ \\
\hline TO-251 & $\mathrm{R} 2$ & $\mathrm{C} 2$ & M2 & $\mathrm{P}[4]$ & 12 & G8 & $\mathrm{A} 2$ & T2 & N2 & E2 & $\mathrm{H} 2$ \\
\hline
\end{tabular}

Table S2 - Nucleotide (nt) identity values among Brazilian rotavirus A (RVA) strains analyzed in the study and RVA prototype strains recovered worldwide. Identity values are available for each of the 11 RVA genes. Data in percentage.

Available at: https://www.dropbox.com/s/ag92c4zxdid9blv/Supplement_2.xlsx?dl=0 
(A)

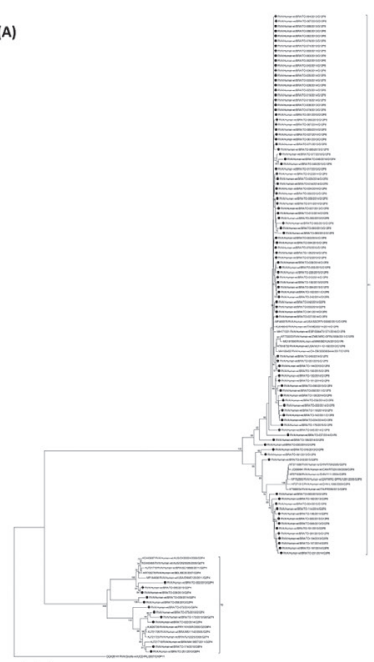

(D)
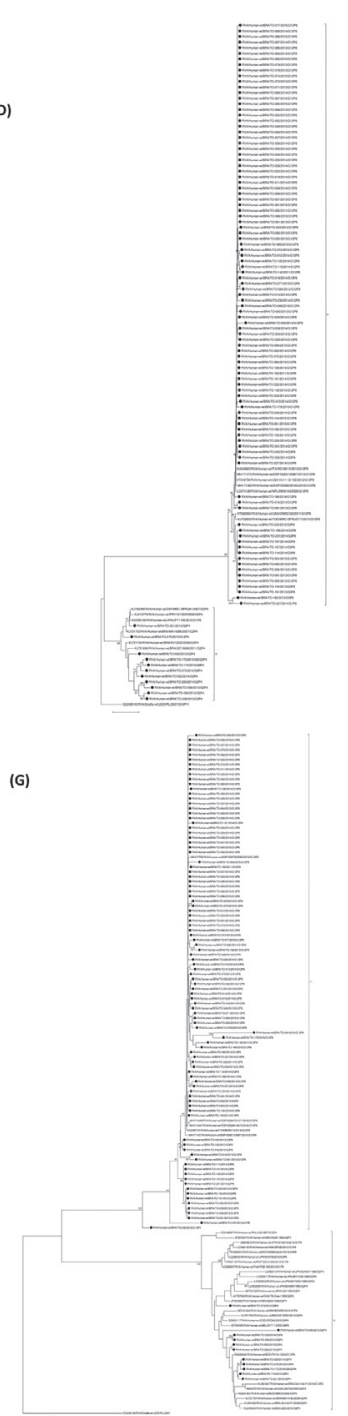

(B)

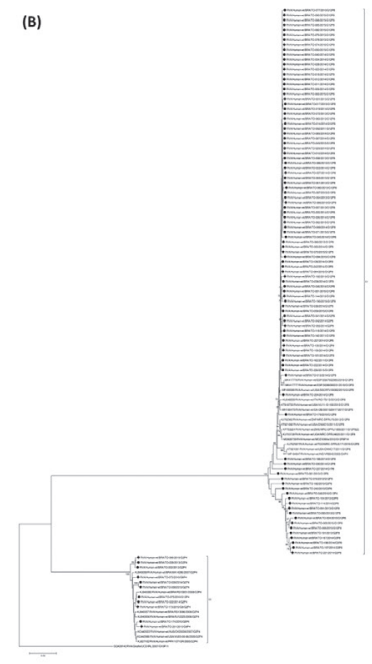

(E)

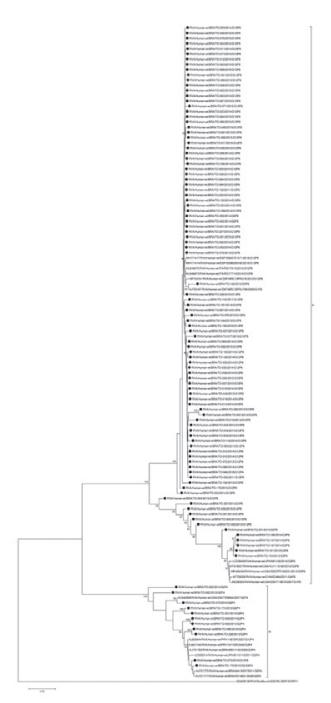

(H)

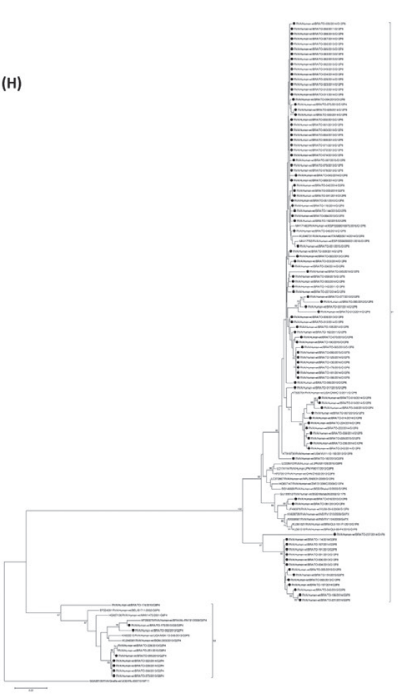

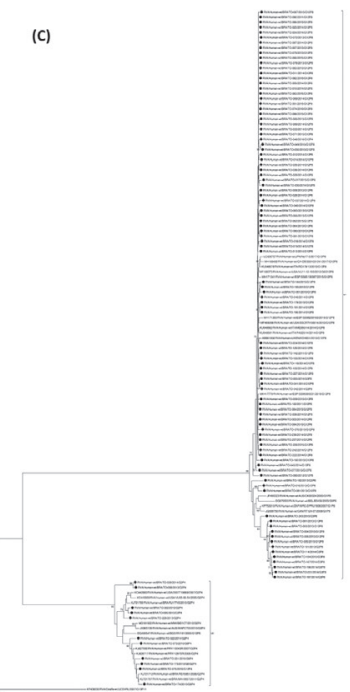

(F)

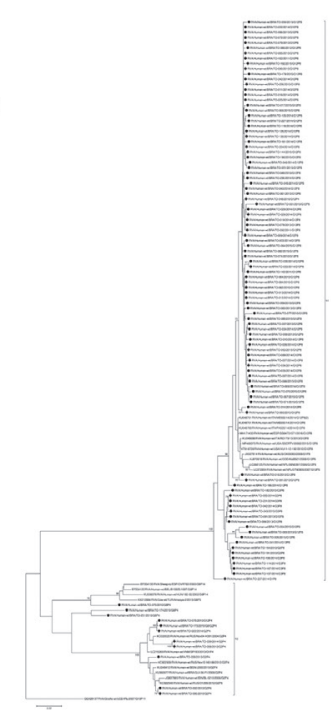

(I)

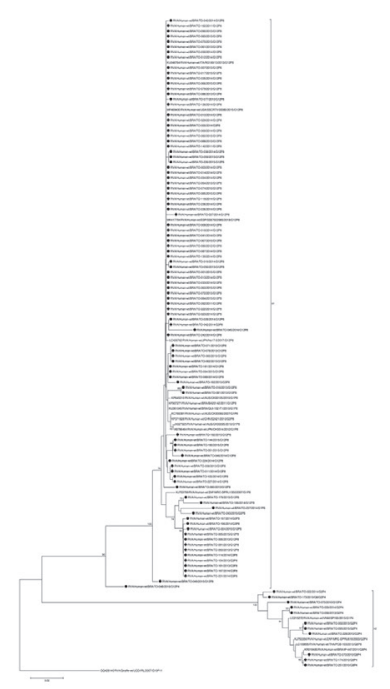

Figure S1 - Phylogenetic analyses based on full VP1-VP3, VP6 and NSP1-NSP5 nucleotide sequences from Brazilian RVA strains detected between 2010 and 2016, and reference RVA strains available at GenBank. Bootstrap values under $80 \%$ are not shown. Genotypes lineages are shown at the right-hand side of each phylogenetic tree. VP1 (A); VP2 (B); VP3 (C); VP6 (D); NSP1 (E); NSP2 (F); NSP3 (G); NSP4 (H) and NSP5 (I). 